WEB ENGINEERING: NEW DISCIPLINE, NEW EDUCATIONAL CHALLENGES

\author{
Symeon Retalis ${ }^{1}$, Yannis Psaromiligkos ${ }^{2}$, Paris Avgeriou ${ }^{3}$ \\ 1- University of Cyprus \\ Department of Computer Science \\ P.O. Box 20537 \\ Tel. ++3572 892246, Fax. ++3572339062 \\ E-mail: retal@softlab.ntua.gr \\ 2- Technological Education Institute of Piraeus \\ General Department of Mathematics \\ Tel. ++301 5381193, Fax. ++3015381351 \\ E-mail: jpsa@teipir.gr \\ 3- National Technical University of Athens \\ Department of Electrical and Computer Engineering \\ Software Engineering Laboratory \\ Tel. ++301 7722487, Fax. ++3017722519 \\ E-mail: pavger@softlab.ntua.gr
}




\title{
WEB ENGINEERING: NEW DISCIPLINE, NEW EDUCATIONAL CHALLENGES
}

\begin{abstract}
The WWW has turned into a development and run-time environment for large-scale and complex applications. Such sophisticated applications are being deployed in increasing numbers without having been developed according to appropriate methodologies and quality standards. The main reason for this ad hoc development philosophy is the lack of specialised training/education on the web engineering subject domain. This domain/discipline is new, still immature and has recently started getting the attention of researchers, developers, and other major players in the web-based application development market and training market. There is now justifiable and increasing concern about the manner in which students and lifelong learners are well educated and trained in this new discipline. It's also only one year ago that few universities have started providing special courses on this discipline and offer seminars to lifelong learners. The Department of Electrical and Computer Engineering at National Technical University of Athens (NTUA) decided to tackle the didactic need on this subject field, by offering to its postgraduate students one semester course called "Internet Publishing". In this paper an overview of the course, its web-enriched delivery method as well as the quantitative and qualitative results extracted after an evaluation study which occurred during the autumn semester 1999-2000, are presented.
\end{abstract}

Keywords: web engineering, evaluation results, web-based courseware

\section{INTRODUCTION-MOTIVATION}

The World Wide Web has ceased being, solely a distribution medium for resources, and has turned into a development and run-time environment for large-scale and complex applications. Such sophisticated applications are being deployed in increasing numbers. However, arbitrary, anarchic approaches and ad hoc methodologies characterize the current state of application development in the Web environment. Effective ways and techniques for ensuring the integrity and maintainability of web applications are lacking [Murugesan 1999].

Web Engineering (WebE) is concerned with the establishment and use of sound scientific, engineering and management principles and disciplined and systematic approaches to the successful development, deployment and maintenance of high quality Web-based systems and applications [WebE 2000].

The WebE discipline is new, immature and has recently started getting the attention of researchers, developers, and other major players in the web-based application development market. There is now justifiable and increasing concern about the manner in which students and lifelong learners are well educated and trained in this new discipline.

Web applications rely on multiple technology layers tightly linked together. To become a successful Web Engineer, one needs to learn about Internet programming (both server-side and client-side programming, e.g. HTML, DHTML, XML, CGI, Javascript, Java applets \& servlets, ASP, JSP), web-servers customisation, web-related database management systems, web site design, web-based systems development process, etc. In higher education today, there is no discipline in the current curriculum that teaches all or even an extensive part of these skills. Even at universities where there are a lot of practical classes, the student would have to make specific choices in courses during his/her studies, such as: programming language courses, database management systems, software engineering and object-oriented design, information systems, networking and Internet protocols, in order to have adequate background as a web engineer. 
It is until recently, in 1998, when the first workshop on Web Engineering was held within the World Wide Conference (WWW7), in Brisbane, Australia. It's also only one year ago that few universities have started providing special courses on the WebE discipline and offer seminars to lifelong learners.

The Department of Electrical and Computer Engineering at the National Technical University of Athens (NTUA) decided to tackle the didactic need emerging on the WebE subject field, by offering to its postgraduate students one semester course called "Internet Publishing". The aim of this course was to offer knowledge of technical nature, i.e. to enhance students Internet and Web programming skills, as well as a theoretical background on the design and development of web-based applications. In fact, the main emphasis has been put on persuading students to alter their modus operandi when creating a webbased application in order for them to follow suitable engineering methodologies. Traditional ex-cathedra teaching method has been used supplemented by open learning methods based on the Web, thus providing an enriched classroom model. This web-based course was engineered from scratch, to assist the learning process, adopting a hybrid model as is often found in academic institutions nowadays.

In this paper we present an overview of the course on the WebE discipline, its delivery method as well as the quantitative and qualitative results extracted after an evaluation study, which occurred during the autumn semester 1999-2000.

The educational community has a lot to learn regarding in what ways technology can enhance the instructional process. While there is a great amount of writing devoted to the research on the impact of technology in education, there are certain gaps in these research efforts, which require further investigation [IHEP 1999]. Among these gaps are the following:

- There is a lack of a theoretical or conceptual framework

- The way different learning styles of students relate to the use of particular technologies, is not taken into consideration

- The feelings and attitudes of the students involved, are not adequately investigated

This paper illustrates an attempt on our behalf to bridge these gaps while challenging to evaluate the enriched learning model.

The structure of the paper is as follows: In section 2 we describe a review of similar courses on the WebE discipline. In section 3, we describe the overview of the NTUA course. Section 4 deals with the results of the evaluation study. Section 5 contains few concluding remarks about the teaching process on the WebE discipline.

\section{LITERATURE REVIEW}

Web Engineering is related to Computer Science, Software Engineering and Information Systems. It draws upon past experiences in software development but is different from these disciplines. This is due to the nature of the tools, languages, skills of the developers and the dynamic nature of the Web environment. Apart from the purely technical skills such as network computing and performance, distributed computing and databases, learners should be trained on new standards and tools relating to the Web, new programming languages, Web site and application development process models [Deshpande et al. 1999].

There are very few educational initiatives in this field at the higher educational sector worldwide. To our knowledge, some of the courses that are related to the WebE discipline are the following (extracts from the courses web site were taken):

- Software Engineering for Web Applications, at MIT.

Website: [http://www.photo.net/teaching/one-term-web.html].

Instructors-developers: Hal Abelson, Michael Dertouzos, and Philip Greenspun.

Description: This is a senior-level class at MIT for students attending a bachelor's or master's degree

in computer science. The students are expected to have an introductory knowledge of computer 
science, to have attended a core software engineering class, and to have an experience of some programming during summer jobs.

Prerequisites: The class does not require any knowledge of particular computer languages or systems, i.e., the students will learn enough about the required tools as the course progresses.

Learning resources: online textbooks, problem sets, lecture notes and video lectures (Web streamed, DVD, or VHS tape).

- Introduction to Web Based Information Systems, at Department of Computing and Information Systems, University of Western Sydney Macarthur, Australia.

Website: [http://webct.bu.edu/public/00sprgengsc500a2/index.html].

Instructor: Professor Roscoe Giles.

Description: The goal of this introductory course is to engage participants in learning about, and experimenting with web information systems. The challenge of the course is to provide students with ideas and understanding of lasting value in an area where the passing of time has not allowed for the best ideas to "settle out." The course will offer more than just skills related to the latest fads on the Internet.

Prerequisites: There are no rigid course prerequisites, however it is expected that experience in either Java or $\mathrm{C}++$ would consist a suitable background. Students should be familiar with the HTML and web operation.

Topics: Web Architecture, Programming for the Web (mainly Java), Server side information services (mainly using XML)

Learning resources: Class lecture-discussions supported by web based reading materials.

- Software Engineering of Web Applications, Department of Electrical and Computer Engineering, Rutgers University.

Website: [http://www.caip.rutgers.edu/ marsic/Teaching/ATCE/syllabus.html]

Instructor: Ivan Marsic.

Description: The course theme is Web software design using Java, XML, and thin clients. The main goal is to engineer software for the heterogeneous Web with mobile and wireless clients.

Prerequisites: Software Engineering I.

Topics: Software components (Java Beans), application frameworks, design patterns, intelligent agents.

Learning resources: There is on-line material available for the course.

- Topics in Networking and Multimedia Applications, Northeast Parallel Architectures Centre (NPAC), Syracuse University.

Website: [http://www.npac.syr.edu/Education/Courses/CPS640/index.html]

Instructors: Dr. Roman Markowski \& Dr. Marek Podgorny.

Description: The primary objective of the course is to provide a comprehensive panorama of networked multimedia applications and the underlying computer and networking technology. The problem set during the course concerns how existing and emerging data communication technologies can meet multimedia application requirements.

Prerequisites: None in specific

Topics: The course covers LAN and WAN Technologies, Bridging, Switching, Routing, Networking Protocols, Management, Design and Security as well as Multicast, Videoconferencing, Multimedia Collaboration Technologies and Audio/Video compression and coding.

Learning resources: On-line lecture notes and resources designed as an introduction to the field and a practical guide for designing and planning networks for multimedia applications. This course is taught using the TANGO Interactive Virtual Classroom-a network-based interactive distance learning system provided by WebWisdom.com.

There is also an MSc program that deals with the WebE discipline, which can be described as follows:

- Master of Information Technology (Web Engineering and Design), Department of Computing and Information Systems, Faculty of Informatics, Science and Technology, University of Western Sydney Macarthur, Campbelltown, Sydney, Australia.

Website: [http://fistserv.macarthur.uws.edu.au/cis/courses/PostGrad.htm] 
Program coordinator: Dr Yogesh Deshpande.

Description: This is one of the three majors of the Master of Information Technology degree, which is designed to meet the needs of business and industry in key areas of information technology. It is offered in one year full-time or two years part-time modes.

Topics: The Web Engineering major deals with Web Technology, Web Site Management and Security, Web-based Application Development, IT for Virtual Organisations and other core subjects.

The aforementioned courses are indicative examples of the way, the various aspects of the WebE discipline can be taught. In the following sections, we describe the approach that the Department of Electrical Engineering, National Technical University of Athens, has adopted. There a number of differences from the above courses such as: the structure of the on-line learning material, the topics of the lectures and the nature of the tutorials. The classroom lectures concerned the theoretical aspects of WebE (design methods, process models, etc). The on-line material was structured as tutorials, which were related to technical issues of the subject field i.e. programming, server customisation, etc. The underlying instructional philosophy was to allow students to acquire technical skills at their own pace with the aid of web-based courseware and peer tutorials (when needed) and to give emphasis on specific development methods for web applications as well as the current trends in research and industry via a series of lectures. The main reasons for offering computer-aided instruction to students on technical skills were two: a) The majority of the students are highly competent in programming, so either they know internet programming or they have the background to advance their skills at their own pace, b) we had a very well-designed courseware which can be easily updated to the constant changes that take place in web-related technologies. On the other hand, it was desirable to offer the theoretical knowledge that could not easily be found in the WebE discipline through classroom lectures (such as development methodologies and complex real-time applications analysed by experts).

\section{COURSE OVERVIEW}

The course on WebE discipline is one semester postgraduate course, starting on October and ending on March. This course belongs to the set of elective courses that a postgraduate student has to attend successfully during his/her Ph.D. studies. After the successful completion of this course, the students are better able to:

- follow systematic methodologies for web application development

- construct interactive, aesthetically attractive and user-friendly Web applications

- state practical web publishing problems and give examples of well designed web applications

Most of the students, who have been awarded full scholarships, have demanding research, development and tutoring obligations during their studies. Thus, it was a necessity to create a flexible learning environment. An enriched classroom model based on the WWW has been developed for the instructional delivery on the WebE discipline [http://webct.softlab.ntua.gr]. The term "enriched" signifies that the open and distance learning methods have been used complementary to the traditional ones. Apart from excathedra lectures, peer tutorials as well as on-line resources such as a web-based courseware and on-line tools that facilitated the fulfilment of learning activities had been developed and integrated into the WebCT [WebCT 2000] learning environment, as supplements. So the students are provided with a variety of teaching aids for acquiring knowledge and skills without many constraints in time and place of instructional delivery.

\subsection{Lectures}

The students attended few lectures (one every two weeks) on the following topics:

- An introduction to web publishing and programming techniques

- Hypermedia design and development methodologies such as OOHDM [Schwabe \& Rossi 1995], RMM [Isakowitz 1995] 
- Development methodologies for specific type of web applications such as web-based courseware, ecommerce

- Ergonomics of web-based applications

- Asynchronous and synchronous multimedia conferencing systems

- Examples of industrial web applications such as one for the Greek stock market, for a digital library and others

Unfortunately the lectures could not be videotaped in order to be available for the student body that could not attend. The presentation slides were integrated into the WebCT as on-line reference material and the students could contact the lecturers for further information. It is with the aims of course organisers during the academic year 2000-2001 to videotape the lectures and offer them via a video-on-demand mechanism.

\subsection{Web-based courseware}

The WWW was used to "add value" to the instructional process as well as to provide a flexible, stimulating and effective learning environment. The WebCT learning environment was the specific technological infrastructure on which the web-based courseware as well as tools for learning activities had been integrated.

The web-based courseware consists of:

- Course description, study guide, and announcements concerning news, deadlines and other events

- An electronic book about programming for the Web, which included the following topics: HTML, Javascript, CGIs \& Perl, topics on setting up and configuration of web servers.

- Sample of an exam paper and its solution

- On-line library with links to resources such as:

- Relevant handbooks on special topics of Internet programming and web publishing

- Papers about development methodologies for web-based applications such as the OOHDM [Schwabe \& Rossi 1995], RMM [Isakowitz 1995], and CADMOS [Retalis \& Skordalakis 2000].

- Topics of discussion about the styles of web design with references to on-line Style Guides.

The electronic book (e-book) was specially developed to be user-friendly, pedagogically effective and aesthetically attractive. The book contains theory, examples as well as self-assessment exercises. The structure of the e-book follows the UK's Open University standards for structuring the learning material into blocks and units, while an indexed guided tour was adopted for navigation purposes. Each block consists of learning objectives in order that the student knows well ahead what to expect from the learning material. The student can practice his/her programming skills on specific exercises with the aid of a customized environment, which included an HTML editor with a built-in preview mechanism and the solutions for the exercises. One of the suggested handbooks for the course (though not obligatory) was the one of [Lowe \& Hall 1999] which concentrates on Hypermedia Engineering.

\subsection{Learning activities}

Project-based learning was the main pedagogical method for this course. The students formed small groups in order to construct web-based applications following specific methodologies. There was a variety of applications proposed to the students as subjects for their projects, such as the development of web sites for a laboratory, company, etc. or e-commerce sites or web-based instructional systems.

The students followed the development methodologies that had been taught during the lectures. The submission of intermediate deliverables and documentation was required. Students submitted them in terms of on-line publications using the appropriate mechanisms of the WebCT learning environment, on specific deadlines and following specific templates. Project deliverables concerned the documentation of the development process, such as requirement specification, design and user manuals. Thus, all project groups could see the progress of the development process of their colleagues and act as peer-reviewers 
when asked by the instructor. Moreover, the on-line submission procedure augmented the collaboration among groups.

Finally, face-to-face and asynchronous communication among tutors and students took place during the course. The tutors were available at specific office hours in order to help and advise students. Personal and group e-mail was the medium for further communication among students and tutors. The tutorials concerned mainly the development process of the project. Only few tutorials were held for elaborating on programming techniques and solving problems. It was already examined over the past years that students were not very keen on using synchronous conferencing systems as a communication medium. The main reason is that they are all located in the same building and they like contacting in person. The tutors also preferred face-to-face meetings rather than synchronous computer-mediated communication when there was a choice. Effort will be made to use a customised ICQ-like tool for synchronous communication in addition to the web-based discussion fora during the following academic year.

\section{EVALUATION STUDY}

The evaluation study followed a specific methodology, called CADMOS-E [Retalis et al. 1998] which is a "pre-test" and "post-test" method incorporating some aspects of the illuminative evaluation approach [Calder 1995]. It is a stepwise method supported by specially developed "pre-test" and "post-test" questionnaires, which provide data for both quantitative and qualitative analysis.

In most evaluation studies, the question in focus concerns the comparative effectiveness of various types of distance learning systems as instructional delivery modes to traditional modes [e.g. Hiltz 1995; Hartley 1994] rather than the innovation of the delivery mode itself and the factors, which may contribute to its effectiveness. Three broad measures of the effectiveness of distance education are usually examined in the original research [IHEP 1999]. These include:

- Student outcomes, such as grades and test scores;

- Student attitudes about learning through distance education;

- Overall student satisfaction toward distance learning.

The focus of this evaluation is on the learning effectiveness of the course and its delivery mode as well as the identification of extensions and revisions that were required to take place. The learning effectiveness was conceptualised as being influenced by a number of variables, such as:

- Usage of the learning environment

- Effect of the instructional delivery mode to students' learning styles

- Contribution of the learning resources to the acquisition of knowledge and skills

- Effect of the instructional delivery mode to the acquisition of knowledge and skills

- Quality of the learning resources

- A comparison of the enriched classroom delivery mode with the traditional ex-cathedra one

All the variables are composite and are measured by multiple items, each measuring a slightly different aspect of the main variable.

\subsection{Subjects}

The total number of postgraduate students who responded to the evaluation study reached up to 16 ( 2 women and 14 men) out of 40 who successfully completed the course. The drop out rate was $21,6 \%$, i.e. 11 students out of the 51 registered did not finish the course. The main reason was that the course was very demanding. All the students had previous experience in using computers (indeed, most of them had significant experience in programming), Internet and the Web and only one of them had attended a course with similar instructional delivery mode in the past. In terms of the time spent accessing the web-based 
learning environment, the majority of the students spent approximately 1-2 hours per week. Finally, none of them had any problem in reading material suggested in bibliography that was written in English.

\subsection{Instruments for Data Collection}

The study was based upon two kinds of questionnaires that were given to the students. The first kind ("pre-test") aimed at identifying the expectations of the learners from the learning effectiveness of course and its delivery mode. This questionnaire was administered during the first days of the course delivery and not later than the first week and consisted of 29 questions. The second kind ("post-test") aimed to deduce overall judgements and criticism on the learning effectiveness. The questions that appeared on the "pre-test" were also replicated in the "post-test" in a rephrased form. However, the latter instrument consisted of a wide number of closed-end questions that were used to evaluate in detail specific issues on the quality of the on-line learning material, the enriched classroom delivery mode and the instructional support provided during the course. It also included a section with a number of open-ended questions to supplement the quantitative data. The open-ended section concerned issues related to students' likes and dislikes towards the learning environment, the deficiencies concerning the enriched classroom model, suggestions for improving the instructional support and the on-line material, etc.

\subsection{Data Analysis}

Since the size of the sample was not statistically appropriate for quantitative analysis we performed a comparative statistical analysis of the data collected from the "pre-test" and "post-test" questionnaires. The basic statistical analysis, which was conducted, depicted the trends of the learners' opinion concerning the learning effectiveness of the course. Moreover, a qualitative content analysis of the second part of the "post-test" questionnaires was performed which helped to infer a number of conclusions concerning the preferences and the dislikes of the learners about the quality of the course delivery, the design of the web-based learning material and the instructional delivery mode.

\subsubsection{Usage of the learning environment}

The usage of the learning environment according to the answers of the students is shown in Table 1 . The answers were measured in a five-point Likert-type scale and they were coded as follows:

$5=$ More than once per week

$4=$ Once per week

$3=$ Sometimes

$2=$ One or two times

$1=$ Never

Table 1. Usage of the learning environment.

\begin{tabular}{|l|c|}
\hline Question & $\begin{array}{c}\text { Mean } \\
\text { (From } \\
\text { Post-test) }\end{array}$ \\
\hline How often did you make use of the e-mail? & 3.8 \\
\hline $\begin{array}{l}\text { How often did you make use of the annotation tool for adding personal notes to the } \\
\text { learning material? }\end{array}$ & 1.2 \\
\hline How often did you make use of the tool for collecting and downloading learning material? & 2.7 \\
\hline $\begin{array}{l}\text { How often did you make use of the facility for searching specific topics about the learning } \\
\text { material? }\end{array}$ & 2.5 \\
\hline How often did you print topics of the learning material? & 2.1 \\
\hline
\end{tabular}


Table 1 indicates that the WebCT tools/facilities, less used, were the personal annotation tool as well as the printing of learning material. On the other hand, students used the mechanism for the collection and downloading of learning material and the search engine much more often. It should be noted that the students did not use the e-mail tool, which is integrated into WebCT, but their preferred e-mail clients and their usual e-mail accounts. The main reason was their need to have one-stop unified e-mail service rather than having a separate e-mail system for this specific course.

Measurement of the students' use of the learning environment was conducted through the embedded administrative tool of the WebCT. This measurement provided an insight of the total number of content pages accessed by each student over the course and the time spent on them. In general, a small group of students spent little time or totally ignored the introductory pages on web publishing and the HTML language. But they did read specific topics on Internet programming (e.g. CGI scripting) and web server customisation. For the rest of the students, there was a little variation in their access and time spent on ebook.

\subsubsection{Effect of the instructional delivery mode to students' learning styles}

The effect of the instructional delivery mode to students' learning styles before and after the course delivery is presented in Table 2. This evaluation study accords with Kolb [http://www.cyg.net/ jblackmo/diglib/styl.html] who showed that learning styles could be seen on a continuum running from:

- concrete experience: being involved in a new experience

- reflective observation: watching others or developing observations about own experience

- abstract conceptualization: creating theories to explain observations

- active experimentation: using theories to solve problems, make decisions

The answers were measured in a five-point Likert-type scale and they were coded as follows:

$5=\mathrm{I}$ absolutely agree

$4=$ I agree

$3=$ Neutral opinion

$2=$ Disagree

$1=\mathrm{I}$ absolutely disagree

Table 2. Effect of the instructional delivery mode to students' learning styles.

\begin{tabular}{|l|c|c|}
\hline Question & $\begin{array}{c}\text { Mean } \\
\text { (From } \\
\text { Pre-test) }\end{array}$ & $\begin{array}{c}\text { Mean } \\
\text { (From } \\
\text { Post-test) }\end{array}$ \\
\hline I pursue learning experiences in a self-directed way. & 3.6 & 2.9 \\
\hline I get bored quickly when I follow detailed instructions as a way of learning. & 3.2 & 3.3 \\
\hline I always search other sources for learning material. & 4.0 & 4.0 \\
\hline The learning material must include examples. & 4.8 & 4.8 \\
\hline $\begin{array}{l}\text { The learning material must include audiovisual components (pictures, } \\
\text { animation, sound, video). }\end{array}$ & 3.9 & 4.1 \\
\hline I prefer to learn the theoretical details of a subject matter. & 3.6 & 3.5 \\
\hline $\begin{array}{l}\text { I appreciate the contribution of other students when studying the subject } \\
\text { matter. }\end{array}$ & 4.3 & 4.5 \\
\hline I prefer to work on projects based on teamwork & 3.8 & 3.9 \\
\hline
\end{tabular}

As shown in Table 2 and by studying the answers of each student separately, we can conclude that the new instructional mode affected the learning styles of students. The majority of the students prefer examples and other sources embedded on the learning material. The content analysis of the responses provided by open-ended questions revealed that the students are motivated from the subject matter but they wanted more sources. However, the on-line learning material included sources that satisfied their 
preferences. Another significant remark is that students don't pursue learning experiences in a selfdirected way; on the contrary, they want the intellectual contribution of other students and collaboration.

\subsubsection{Contribution of the learning resources to the acquisition of knowledge and skills}

Another important factor measured during the evaluation study was the contribution of the learning resources to the acquisition of knowledge and skills, both as expected before and as criticised after the completion of the course delivery. The question was: "Did the following resources of the learning environment help the acquisition of knowledge and skills?". The answers were measured in a five-point Likert-type scale and they were coded as follows:

$5=$ Very important

$4=$ Important

$3=$ Neutral opinion

2=Unimportant

$1=$ Very unimportant

Table 3. Contribution of the learning resources to the acquisition of knowledge and skills.

\begin{tabular}{|l|c|c|}
\hline Question & $\begin{array}{c}\text { Mean } \\
\text { (From } \\
\text { Pre-test) }\end{array}$ & $\begin{array}{c}\text { Mean } \\
\text { (From } \\
\text { Post-test) }\end{array}$ \\
\hline On-line electronic book. & 4.5 & 4.1 \\
\hline $\begin{array}{l}\text { References to on-line learning material existing in electronic library or provided } \\
\text { during the course. }\end{array}$ & 4.5 & 4.0 \\
\hline The extra learning material provided during the course. & $*$ & 3.8 \\
\hline Discussions on the subject matter with other students by e-mail. & 3.8 & 2.3 \\
\hline Discussions on the subject matter with teachers and assistants by e-mail. & 4.2 & 3.8 \\
\hline $\begin{array}{l}\text { The material derived from discussions on the subject matter among students by } \\
\text { e-mail (only the reading of messages not the participation). }\end{array}$ & $*$ & 2.5 \\
\hline $\begin{array}{l}\text { The material derived from discussions on the subject matter between students } \\
\text { and teachers/assistants by e-mail (only the reading of messages not the } \\
\text { participation). }\end{array}$ & $*$ & 2.4 \\
\hline Past exam papers and solutions. & 4.2 & \\
\hline The development of assignments. & 4.3 & 3.0 \\
\hline The study of intermediate deliverables developed by other groups. & $*$ & 3.2 \\
\hline
\end{tabular}

* question not available in "pre-test"

From the above table, the answers and the comments of the students as well as the usage statistics of each learning resource, the following can be deduced:

- Both the e-book and the references to on-line learning material existing in the virtual library or provided during the course successfully contributed to the acquisition of knowledge and skills. It should be noted that there were many complimentary remarks on the open-ended questions of the "post-test" questionnaire.

- The students expected more from the discussions on the subject matter with other students and the tutors. To some degree this is due to the students' enthusiasm when they are going to attend a new mode of teaching. This expectation also shows that the tutors should raise more questions for discussion while in parallel they should answer frequently to student queries and they should give them more material for feedback.

- As expected the assignments contributed a great deal in increasing the students' knowledge and skills because they were closely related to the learning objectives of the course. However, the study of the intermediate deliverables submitted by other groups didn't increase student collaboration because most of the students delivered them just on time. 


\subsubsection{Effect of the instructional delivery mode to the acquisition of knowledge and skills}

Tables $4 \mathrm{a}$ and $4 \mathrm{~b}$ below exhibit the evaluation of the effect of the instructional delivery mode to the acquisition of knowledge and skills. The measurement included a number of criteria such as easiness, usability, motivation, richness and communication. The answers were measured in a five-point Likerttype scale and they were coded as follows:

$5=I$ absolutely agree

$4=$ I agree

$3=$ Neutral opinion

2=Disagree

$1=$ I absolutely disagree

Table 4a. Evaluation of the effect of the instructional delivery mode to the acquisition of knowledge and skills including pre- and post-test questions

\begin{tabular}{|l|c|c|}
\hline Question & $\begin{array}{c}\text { Mean } \\
\text { (From } \\
\text { Pre-test) }\end{array}$ & $\begin{array}{c}\text { Mean } \\
\text { (From } \\
\text { Post-test) }\end{array}$ \\
\hline It was easy to attend the instructional delivery mode & 4.3 & 4.3 \\
\hline The instructional delivery mode widened student-instructor communication. & 3.8 & 3.3 \\
\hline $\begin{array}{l}\text { The instructional delivery mode alleviated the physical constraints of } \\
\text { attending face-to-face lecturing. }\end{array}$ & 4.8 & 4.2 \\
\hline $\begin{array}{l}\text { The instructional delivery mode increased the potential to pursue } \\
\text { collaborative project work with other students. }\end{array}$ & 3.4 & 2.9 \\
\hline The instructional delivery mode increased my interest in the subject matter. & 3.9 & 4.3 \\
\hline $\begin{array}{l}\text { The instructional delivery mode provided immediate and easy information } \\
\text { relevant to the subject matter. }\end{array}$ & 4.6 & 4.6 \\
\hline
\end{tabular}

For this specific variable, the "post-test" questionnaire was more extensive.

Table $4 \mathrm{~b}$. Evaluation of the effect of the instructional delivery mode to the acquisition of knowledge and skills including only "post-test" questions

\begin{tabular}{|l|c|}
\hline Question & $\begin{array}{c}\text { Mean } \\
\text { (From } \\
\text { Post-test) }\end{array}$ \\
\hline A variety of learning experiences were provided through the instructional delivery mode & 4.1 \\
\hline $\begin{array}{l}\text { The mode of communication through the web-based learning environment helped me to } \\
\text { solve problems and answer questions that appeared during the course. }\end{array}$ & 3.4 \\
\hline $\begin{array}{l}\text { The instructional delivery mode allowed me enough freedom to choose where, when and } \\
\text { how to study. }\end{array}$ & 4.6 \\
\hline The instructional delivery mode increased active participation in classroom activities. & 3.4 \\
\hline $\begin{array}{l}\text { The instructional delivery mode encouraged me to participate actively in normal class } \\
\text { activities with other students. }\end{array}$ & 2.9 \\
\hline $\begin{array}{l}\text { It was easy to learn and make use of the instructional delivery mode and it was not required } \\
\text { training by the instructors/assistants. }\end{array}$ & 4.5 \\
\hline
\end{tabular}

From the above tables and the answers and comments of the students from the open-ended questions of the "post-test" questionnaire we conclude that the teaching mode through the WebCT learning environment:

- succeeded in facilitating the flow of information about the course.

- offered a variety of ways to acquire knowledge and learning experiences.

- was characterized as easy to attend without requiring any additional training and therefore its learning effectiveness was increased.

- did not encourage the students enough to participate actively in normal class activities with other students due to lack of well-formed questions for discussions. 
- did not widen student-instructor communication, as the students expected. However, studying the open-ended questions of the "post-test" questionnaire revealed that the lack of many subjects for discussions as well as the fact that some answers to students' queries were given personally without update to discussion lists, drove the students to grade low on this question.

- increased the student interest in the subject matter although they had cautiously answered before the usage of the learning environment. This shows that the new mode of teaching was generally successful.

\subsubsection{Quality of the learning material}

Table 5 shows how the students evaluated the quality of the learning material. The measurement included a number of criteria such as aesthetics, transparency, forgiveness, dissemination of information, seamless of content and learning experiences [Tessmer 1995]. The answers were measured in a five-point Likerttype scale and they were coded as follows:

$5=I$ absolutely agree

$4=$ I agree

$3=$ Neutral opinion

$2=$ Disagree

$1=\mathrm{I}$ absolutely disagree

Table 5. Evaluation of the quality of the learning material.

\begin{tabular}{|l|c|}
\hline Question & $\begin{array}{c}\text { Mean } \\
\text { (From } \\
\text { Post-test) }\end{array}$ \\
\hline The aims and objectives of the learning material were clear. & 3.6 \\
\hline The learning material included in the on-line book explained things clearly. & 3.4 \\
\hline The extra learning material provided during the course explained things clearly. & 3.5 \\
\hline No effort spent in memorization of topics of the on-line learning material. & 4.1 \\
\hline It was easy to find out what was expected in the on-line learning material. & 3.5 \\
\hline The assignments on the course were appropriate to the learning objectives. & 4.0 \\
\hline The on-line learning material was presented in an attractive way. & 3.8 \\
\hline $\begin{array}{l}\text { The structure of units/blocks in the on-line learning material made the study and } \\
\text { assimilation of the subject matter easy. }\end{array}$ & 3.5 \\
\hline The on-line learning material could be easily read. & 3.8 \\
\hline The structure of the resources of the on-line learning material was seamless & 3.8 \\
\hline The way of browsing the on-line learning material was clear and easy to use. & 4.1 \\
\hline I had the opportunity to demonstrate/practice what I had learned. & 3.5 \\
\hline The on-line learning material included enough case studies. & 3.1 \\
\hline The on-line learning material was interactive (not only through browsing) & 3.4 \\
\hline $\begin{array}{l}\text { Invalid selections during browsing of the on-line material or during the usage of the new } \\
\text { environment could be easily corrected. }\end{array}$ & 3.5 \\
\hline The navigation schema of the on-line learning material was very good & 3.7 \\
\hline There were motivations and material to communicate with tutors and students. & 3.4 \\
\hline I developed skills on the subject matter thanks to the on-line learning material. & 3.3 \\
\hline
\end{tabular}

As shown in Table 5 we can conclude the following:

- The learning objectives of the material were in general clear. Moreover, the usage of the material wasn't spent in memorization and the learning material motivated the students to actively participate in classroom and/or peer tutorial activities. Nevertheless, there were not many well-formed questions for discussion.

- The learning material was characterized by usability and it was aesthetically attractive. 


\subsubsection{Comparison of the new mode of teaching with the conventional one}

There were some critical questions where the students were asked to compare the conventional way of teaching against the enriched teaching mode through the WebCT learning environment. Also, the students were asked an overall evaluation of the teaching mode. Table 6 presents the mean of each measurement. The answers were measured in a five-point Likert-type scale and they were coded as follows:

$5=$ I absolutely agree

$4=$ I agree

$3=$ Neutral opinion

$2=$ Disagree

$1=$ I absolutely disagree

Table 6. Evaluation of the teaching modes.

\begin{tabular}{|l|c|}
\hline Question & $\begin{array}{c}\text { Mean } \\
\text { (From } \\
\text { Post-test) }\end{array}$ \\
\hline As a whole, I am satisfied with my experience of the WebCT learning environment. & 4.3 \\
\hline $\begin{array}{l}\text { The new mode of teaching through the WebCT learning environment provides more and } \\
\text { better learning experiences than the conventional way of teaching. }\end{array}$ & 3.9 \\
\hline $\begin{array}{l}\text { The new mode of teaching through the WebCT learning environment motivated me for } \\
\text { further study on the subject matter. }\end{array}$ & 3.2 \\
\hline $\begin{array}{l}\text { The combination of the new mode of teaching with the conventional one seemed to be } \\
\text { more beneficial than the usual way of teaching. }\end{array}$ & 4.1 \\
\hline $\begin{array}{l}\text { As a whole, I am satisfied with my experience of the combination of the new mode of } \\
\text { teaching with the conventional one. }\end{array}$ & 4.2 \\
\hline
\end{tabular}

Question: Would you prefer to attend again a course, which combines the conventional way of lecturing with the new mode of teaching in the feature?
Answer:
Yes: 15
No: 1

Question: Which mode of teaching was more useful?

Answer: Through the WebCT environment: 14 Conventional way of teaching: 2

The students' experience from the usage of the new mode of teaching through the WebCT learning environment was positive and it was clearly better than the conventional way of teaching. The advantages and disadvantages derived from the analysis of the qualitative data are mentioned below:

Advantages

- Easy acquisition of information related to the course.

- Lack of restrictions in time and place in terms of communication with the tutors and studying of the learning material.

- Selective collection of the learning material for downloading or printing.

- Usability of the learning material.

- The existence of case studies.

\section{Disadvantages}

- The elaborated case studies on the hypermedia development methodologies were limited.

- There were not many subjects for discussions.

- Some answers to students' queries were given personally without update to discussion list.

\section{CONCLUDING REMARKS}


It is evident that the web has become an integration platform for distributed applications. The design, constructing and maintenance of such applications are not easy tasks. People wishing to develop web applications of high quality need special training on the WebE discipline, which covers a variety of topics. Recently courses on the WebE discipline have arisen. The NTUA offers such a course whose traditional classroom based delivery mode is enriched with on-line learning resources integrated into the WebCT environment. The evaluation study showed that NTUA staff succeeded in offering a high quality course, which was appropriate for the student body for which it was intended. The flexible and open learning mode was the most suitable for NTUA 's postgraduate students who have extensive obligations aside their research duties. The upgrade of the learning material and its delivery mode will be focused on the development of on-line case studies relevant to the subjects of assignments as well as the development of more extensive examples on specialised topics of internet programming. Great care will be paid to the design of learning activities and the training of tutors on triggering and encouraging students' participation to computer mediated communication and collaboration.

\section{BIBLIOGRAPHY}

Calder, J. (1995), Programme Evaluation and Quality: A Comprehensive Guide to Setting up an Evaluation System, Institute of Educational Technology, Open University, Kogan Page.

Deshpande, Y., Hansen, S. and Murugesan, S. (1999), "Web Engineering: Beyond CS, IS and SE. An evolutionary and non-engineering perspective", Proceedings of the First ICTE Workshop on Web Engineering, International Conference on Software Engineering, Los Angeles, 16-17 May 1999.

Institute for Higher Education Policy (1999). What's the Difference: A Review of Contemporary Research on Effectiveness of Distance Learning in Higher Education, [http://www. Ihep.com/PUB.htm]

Isakowitz, E., Stohr, A., and Balasubramanian, P. (1995), "RMM: A Methodology for Structured Hypermedia Design", Communications of the ACM, Vol. 35 (8), August 1995.

Lowe, D., and Hall, W. (1999), Hypermedia \& the Web: An Engineering Approach, John Wiley \& Sons Ltd.

Murugesan, S. (1999), "Editorial", ACM SIGWEB Newsletter, Vol. 3 (3), October 1999.

Retalis, S., Makrakis, V., and Skordalakis, E. (1998), "A methodology for evaluating the effectiveness of the use of new technologies in ODL", Proceedings of EDMEDIA-EDTELECOM'98, Freiburg, Germany.

Schwabe, D., and Rossi, G. (1995), "The Object-Oriented Hypermedia Design Model (OOHDM)", Communications of the ACM, Vol. 35 (8), August 1995.

M. Tessmer (1995). Formative Multimedia Evaluation, Training Research Journal, Vol. 1.

WebCT (2000). WebCT Home page, [http://www.webct.com]

WebE (2000), Web Engineering Home Page [http://fistserv.macarthur.uws.edu.au/san/WebEhome/] 